\title{
Um enfrentamento à opacidade do mundo
}

\section{Roger Andrade Dutra}

\section{(2) OpenEdition}

\section{Journals}

Edição electrónica

URL: http://journals.openedition.org/rccs/1582

DOI: $10.4000 /$ rccs. 1582

ISSN: 2182-7435

\section{Editora}

Centro de Estudos Sociais da Universidade de Coimbra

Edição impressa

Data de publição: 1 setembro 2011

Paginação: 119-122

ISSN: 0254-1106

\section{Refêrencia eletrónica}

Roger Andrade Dutra, «Um enfrentamento à opacidade do mundo », Revista Crítica de Ciências Sociais [Online], 94 | 2011, posto online no dia 01 outubro 2012, consultado o 22 setembro 2020. URL : http:// journals.openedition.org/rccs/1582 ; DOI : https://doi.org/10.4000/rccs.1582 


\section{Recensões}

\section{Martins, Hermínio (2011), Experimentum Humanum: civilização tecno- lógica e condição humana. Lisboa: Relógio d'Água, 448 pp.}

Um enfrentamento à opacidade do mundo A publicação de Experimentum Humanum, de Hermínio Martins, representa um desafio às lógicas da opacidade do mundo e da inevitabilidade do progresso tecnocientífico. Se os tecnólatras poderão dar-se à comodidade de o ignorar, o mesmo não se poderá dizer do campo dos críticos da contemporaneidade.

O livro é composto por nove capítulos, em três subseções: "Pensar a técnica: questões preliminares", "Do trágico tecnológico" e "Passagem para o pós-humano". Aqueles habituados à prosa de Hermínio Martins, reencontrarão a diversidade temática $\mathrm{e}$ exames nunca superficiais. Schopenhauer dizia, a propósito de Espinosa e Hegel, que os textos obscuros repercutem a obscuridade das ideias de seu autor. Sem dúvida, não é o caso dos ensaios de Martins, em que capacidade de síntese e elegância textual mostram-se em parágrafos intelectualmente vertiginosos. $\mathrm{O}$ primeiro leitor constatará seu conhecimento enciclopédico da literatura em humanidades: vai de Plotino, Teofrasto e Aristóteles até Comte, Marx, Keynes, Popper ou Lovelock. Em Martins, a erudição não é exibicionista, ela não serve o erudito mas, sim, o pensamento crítico.

Frequentemente, o mundo nos parece inapreensível, opaco. Mas isso é porque confundimos complexidade com incognoscibilidade. E, segundo o Experimentum Humanum, a contrapartida de nossa explosão de conhecimento é uma "produção lateral concomitante de desconhecimento, ignorância ou nesciência" (Martins, 2011: 160). Se algo decorreu do relativismo e do individualismo metodológico foi o húbris da opinião, a consagração do direito de dogmatizar: o mundo é opacificado também porque indivíduos exilados tornam-se refratários à controvérsia. E como produzir conhecimento assim? A resposta é, antes de tudo, uma predisposição moral: a crença de que conhecer é sempre possível. Um ethos cartesiano radicado na dúvida metódica é o centro irradiador do Experimentum $\mathrm{Hu}$ manum: enfrentar a opacidade do mundo adotando a controvérsia metodológica. Os temas se sucedem, se interpenetram, sem que o autor fuja às suas implicações. Por que deveríamos, pergunta, com respeito aos processos tecnocientíficos, alicerçar o Princípio da Precaução em uma lógica das incertezas e não na lógica do risco? Ora, porque esta baseia suas posições de precaução em cálculos probabilísticos. Já a lógica da incerteza ancora-se no reconhecimento de que diversos processos tecnocientíficos de larga escala, se escaparem ao seu curso esperado de funcionamento, serão incontroláveis. De acordo com Martins, o que causa perplexidade, face ao apelo à segurança "comprovada" pelo cálculo de probabilidades é, sobretudo, o próprio ineditismo dos sistemas tecnocientíficos omniabrangentes. Como construir séries estatísticas para situações sempre novas? Será uma probabilística do evento único? Como não há garantia de que nós humanos gozamos de privilégio cósmico, de que o Universo dependa de nossa existência para que ele próprio subsista, submeter-se voluntariamente a esta exceção não tem nada de racional (Martins, 2011: 218-9). 
É curioso ver pensadores vinculados às humanidades recorrendo à estatística. Comte, no século XIX, já denunciava o uso indiscriminado das matemáticas. Os objetos das humanidades são singulares; não cabia à época de Comte, continua descabido, trocar o exame exaustivo por cadeias lineares regressivas ou causais. Atualmente, pouco a pouco, o algoritmo arranca às matemáticas o privilégio de ser tido simultaneamente como modo de existência da ordem subjacente e sua chave explicativa. É a rendição à "palavra de ordem da metafísica informacionalista" (Martins, 2011: 317) que pontifica que "ser é ser computacional” (Martins, 2011:316-7) ou que, recordando Quine, "to be is to be the value of a variable" (apud Martins, 2011: 317). Nela, os fluxos tomam o lugar que já foi das quantidades mensuráveis; toda contingência é algorítmica e todos mal passamos de arranjos de fluxos informacionais. Não há singularidade, só formas diferentes de organização. A metafísica informacionalista nos reduz a amontoados biológicos contingentes (Martins, 2011: 319), acidentais, não-necessários.

Em "Tecnociência e Arte" são discutidas as relações entre cientistas e artistas modernistas. Teria havido, na passagem do século XIX ao XX, uma disputa pelo poder espiritual e pelo poder secular, um litígio pelo direito de ser porta-voz da metafísica da modernidade. Comparando os ciberartistas aos modernistas, Martins conclui que, diferentemente destes, que

atacaram, directa ou indirectamente, a ambição da ciência e da tecnologia ao domínio do mundo", [...] o traço mais notável do movimento da ciberarte e dos seus manifestos é o seu caráter acrítico. Enquanto Rimbaud e os surrealistas proclamavam a necessidade de "changer la vie", o mote dos ciberideólogos, na arte ou não, pode bem ser: "abolir l'bumain". (Martins, 2011: 163-4)
Um diagnóstico semelhante é feito a respeito da bioética. Segundo Martins,

a bioética tornar-se-á uma mera tecno-ética conformista se os bioeticistas não assumirem posições de crítica fundamental tanto das propostas como das práticas biotecnológicas já estabelecidas [...] De que tipo de ética se trata, quando o normativo coincide tanto com o factual? (Martins, 2011: 300)

Se surge a possibilidade de atualizar, de fazer coincidir o simbólico e o factível, é aí que a necessidade do autocontrole se impõe. Se Martins tem razão ao apontar que, face à assunção do "Princípio de Plenitude Tecnológica: [pelo qual] tudo o que é tecnologicamente possível, será realizado, se ainda não o foi" (Martins, 2011: 294), uma bioética que se satisfaça em ritualizar, ao invés de normatizar, ainda precisa mostrar sua serventia. Como uma bioética sancionadora enfrentará a nova eugenia? Chegará o tempo em que talvez precisemos postular "uma vontade global de permanecer uma espécie"? (Martins, 2011: 420). A nova eugenia, viável ou não, já determina comportamentos. É similar ao ocorrido nas sociedades de socialismo real: tudo se passou como se elas fossem fiéis ao socialismo idealizado. A microeugenia de mercado é também um como se, um trágico como se. Se tecnicamente possível, espera que o mercado gere um equilíbrio genético; se não for tecnicamente viável, ou se não o for em sua totalidade, ainda modifica importantes categorias sociais, porque mantém legítima a assimetria distributiva que todo padrão referencial introduz em contextos de diversidade. Em um momento decisivo, quando muitos na Europa parecem facilmente prontos a desembarcar de seu projeto multiculturalista, não deixa de ser preocupante que o delírio tecnocientífico neoeugênico espreite as consciências, 
prometendo perfeição como compensação à escassez da tolerância. Daí, estipular a urgência de que

o Prometeanismo Iluminista precisa de ser corrigido e reformado porque se confunde cada vez mais, na prática, paradoxalmente, com o Faustianismo anti-Iluminista. (Martins, 2011: 322)

Em certa altura, a propósito dos impactos ambientais provocados pelas tecnociências, Hermínio recorda "a incidência da acrasia ou a 'fraqueza da vontade', tema da psicologia moral aristotélica" (Martins, 2011: 223) que tipifica nossas condutas. Agimos conscientes de sua hostilidade à integridade ambiental. A conduta acrática é a do consumidor, com sua racionalidade idiotes, utilitarista, que, em busca do baixo preço, remete todo o ônus ao futuro.

A relação temporal entre a mercadoria e a produção de conhecimento é ditada pela dilação da propriedade mercantil sobre a propriedade epistêmica: Hermínio relembra Popper, que via as sociedades do socialismo real como obstáculos à produção de conhecimento científico, não apenas porque ideologizavam teorias, mas também porque ao acelerarem a concretização de resultados tecnológicos (Martins, 2011: 216) sacrificavam o tempo da acumulação da experiência. É irônico que o que seria uma filosofia da tecnologia antecipada contivesse algo similar ao Princípio da Precaução, uma ética para a era tecnocientífica. Em uma passagem não menos do que brilhante, Martins denomina bodiocentrismo (Martins, 2011: 114) o presente dilatado, extenso. As três grandes categorias da nossa época, o tempo, a energia e a informação, relacionam-se em um sistema de trade-offs no qual a intensificação de qualquer uma só pode ocorrer às expensas das demais. Por isso, nossa sensação de escassez do tempo. Inelástico, ele parece menos disponível porque é o insumo de sociedades geradoras de excedentes informacionais e exponencialmente energívoras (Martins, 2011: 288). Donde uma de nossas utopias contemporâneas ser tektópica, a ânsia por "um regime ideal de energia dotado de fontes de energia efectivamente infinitas, baratas, fiáveis e seguras, destituídas de efeitos secundários ambientais intratáveis, indesejados e imprevistos" (Martins, 2011: 47-8). O poder explicativo desta passagem é imensurável. Convido o leitor a imaginar compensações baseadas na comutabilidade proposta: consuma menos energia, em qualquer forma, menos petróleo, menos eletricidade; ou consuma menos informação, desligue seu telemóvel, reduzindo informação e energia. Então, responda: não terá tido a sensação de ter ganhado mais tempo?

É um problema de primeira ordem determinar se a ambição tecnocientífica pela universalidade é contingente ou se, por outro lado, é ideológica, resultando de sua maneira própria de categorizar os elementos por meio dos quais percebemos o mundo. Analogamente, é similar àquele do ensino da historiografia em sistemas políticos totalitários: variava da negação simples de qualquer coisa digna de ser conhecida antes dos eventos que teriam levado à existência daquele específico estado de coisas, até uma mais sofisticada reformatação de todo o passado, fazendo do presente uma inevitabilidade. Este tipo de abordagem do passado só é eficaz a médio prazo porque, no limite, toda negação do passado é impotente ao fato de que novas memórias acabam sempre elaboradas. Resulta que um sistema como esse só sobrevive por meio de uma contínua negação do passado e da supervalorização do presente como única experiência válida, do presente como sendo simultânea, e paradoxalmente, o ponto alcançável mais alto ou longínquo e onde, mesmo assim, não é moralmente 
permitido parar ou descansar. Também a metafísica tecnocientífica reclama inevitabilidade, na medida em que o conhecimento construído mostra-se como obedecendo a uma única sequência lógica. Acima de tudo, só ele manteria a relação de mutualidade excludente com as suas alternativas. $\mathrm{O}$ que, ao fim e ao cabo, exige a negação de toda contingência. Mas a dialética da existência corresponde a duas realidades contraditórias, mas solidárias e em devir: a contingência histórica produz-se pari passu à relativa estabilidade e durabilidade, à incontingência transitória da realidade vital. É esta dialética que o experimentum bumanum - biotecnológico, eugênico, ambiental, informacional, etc. - quer abolir e é contra isso que o Experimentum Humanum de Hermínio Martins emerge como um de seus mais consistentes desafiantes.

\section{Roger Andrade Dutra}

\section{Tavares, Manuela (2011), Feminismos: percursos e desafios (1947-2007). Lisboa: Texto, 746 pp.*}

O livro Feminismos: percursos e desafios (1947-2007) resulta da tese de doutoramento de Manuela Tavares, investigadora do Centro de Estudos das Migrações e Relações Interculturais (CEMRI) e ativista na União de Mulheres Alternativa e Resposta (UMAR). A autora iniciou a investigação académica neste campo há vários anos, tendo já publicado, em 2000, Movimentos de mulheres em Portugal.

Este novo e extenso volume é uma obra pioneira que apresenta uma abordagem histórico-sociológica e que vem colmatar uma lacuna na investigação nacional. Como é possível ler-se na contracapa, tem como objetivo principal "traçar os percursos dos feminismos em Portugal em meio século de História”. Uma tarefa árdua e desafiante, a qual é explicada sobretudo pela perda de 'memória histórica' que o regime do Estado Novo trouxe consigo e que se perpetua em muitos casos até aos dias de hoje.

A obra está dividida em três partes: na primeira explora-se o enquadramento conceptual, estando já este alicerçado na análise de documentos escritos e fontes orais, traçando a evolução da sociedade e dos feminismos em Portugal desde a década de 1950; na segunda apresenta-se um estudo empírico com estudantes; e na terceira há uma síntese conclusiva sobre a evolução da teoria feminista e da necessidade de reconfiguração das correntes, onde se levantam algumas interrogações advindas da contemporaneidade

A autora inicia com o mapeamento dos feminismos desde a década de 1950 , período esse marcado pela ditadura e pela diluição do ativismo feminista nas movimentações sociais antifascistas. A caracterização das vivências salienta a importância da instrumentalização ideológica para mostrar que as mulheres pertenciam à esfera doméstica e que o regime necessitava do seu apoio enquanto guardiãs da família e dos bons costumes. A autora, à guisa de outros estudos, salienta a importância de não se confundirem as associações femininas, criadas pelo próprio regime para veicular os seus ideais, com as associações feministas. Continua explicando as especificidades do contexto português, que permanece impenetrável às ideias de vanguarda vindas do exterior e que fazem a apologia da emancipação das mulheres e dos valores

\footnotetext{
* Por vontade da autora, este texto segue a nova ortografia.
} 
associados aos feminismos de segunda vaga. É nesta fase que começa a engrossar a oposição ao Estado Novo, em que as mulheres tiveram um peso relevante, sobretudo pelo aumento da participação no mercado de trabalho, consequência da Guerra Colonial e da ida dos homens para a arena de combate.

Os anos 1970 são descritos por Manuela Tavares como a "década de mudanças" (p. 175), protagonizada pela escrita de $A s$ novas cartas portuguesas, obra polémica que viria a mostrar a vitalidade das ideias feministas. Porém, estas tornam-se mais visíveis a nível externo do que em Portugal, criando uma rede de solidariedade impressionante. Mas é precisamente nesta fase que as mulheres começam a ascensão para a esfera pública, estando presentes nas movimentações da época, nas páginas dos jornais e nas revistas, na criação de associações que lutassem pelos seus direitos. Curiosamente, a sua presença fica diluída nas manifestações mais gerais e a ligação aos primeiros feminismos parece estar esquecida. É neste cenário de alguns avanços, mas também de alguns retrocessos, que se entra nos anos 1980. Esta época é igualmente marcada pelo posicionamento da igualdade na agenda política internacional com a criação de várias iniciativas, como por exemplo a Década da Mulher (1975-1985), a oficialização pelas Nações Unidas do Dia Internacional da Mulher (1977), a criação do Ano Internacional da Mulher (1975), a par dos mecanismos institucionais. No caso português destaca-se a emergência de algumas associações, dos organismos estatais de promoção da igualdade e das lutas menos ortodoxas que aparecem no seio dos movimentos, como é o caso do aborto. Este tema vai marcar a agenda dos feminismos em Portugal ao longo das décadas. É nesta fase que a autora também dá voz a mulheres com percursos conhecidos na vida pública e que nunca negaram o ativismo feminista, como é o caso de Maria de Lourdes Pintasilgo, Maria Teresa Horta, Maria Antónia Palla e Maria Alzira Lemos. Dos anos 1990 até à atualidade Manuela Tavares ressalta a criação de redes transnacionais e a projeção de um discurso plural, multiforme e abrangente, que posiciona os feminismos num elevado nível de complexidade. Se muitas conquistas são evidentes, outros desafios se colocam, sobretudo a reconfiguração de uma agenda feminista que responda às preocupações vividas num mundo dominado pelo capitalismo e pela globalização.

Em termos de estudo empírico, e para complementar toda a análise já efetuada com o recurso a documentos e a testemunhos dos diversos períodos e áreas que se cruzaram e continuam a cruzar com os feminismos em Portugal, a investigadora estudou a forma como as/os estudantes do ensino secundário olham para estas questões. Ao conceptualizar a escola como um local que permite a (re)produção de (des)igualdades, Manuela Tavares foca o cerne do processo educativo, procurando respostas para diversas e complexas problemáticas. Através da aplicação de questionários e da realização de entrevistas a estudantes do $12 .^{\circ}$ ano de escolas de Almada e Viseu, aborda questões relacionadas com a consciência das discriminações, a partilha das tarefas domésticas, a violência, as sexualidades, o significado do feminismo, entre outras. Em traços muito gerais conclui que existem diferenças de opinião entre raparigas e rapazes em várias áreas. Destaca-se o facto de elas terem maior noção das desigualdades ao longo da vida. Outro aspeto interessante são os perfis mais evidentes em termos de posicionamentos feministas: uma grande parte adota o feminismo tácito, isto é, defende os direitos das mulheres, mas não se assume como feminista. Estes dados revelam 
conclusões que merecem um maior aprofundamento, uma vez que aqui está mais uma vez patente a falta de memória histórica e necessidade de desmistificar o que se entende por feminismos.

$\mathrm{Na}$ parte final do livro, a autora reflete sobre a necessidade de reconfigurar as correntes feministas, a par de uma maior articulação das diversas esferas onde os feminismos confluem em termos de analíticos e de reflexão, como são as organizações não-governamentais e as universidades. Defende que já não se pode recorrer à tipologia das correntes tradicionais e avança com novas designações, um aspeto inovador do livro. Aqui salienta-se o "feminismo de agência ou de intervenção social” (p. 652), que prima pela articulação das/os várias/os atoras/es sociais, fazendo o contraponto com o feminismo institucional, mas sem correr o risco da absorção.

Termina frisando que é preciso ajudar na construção deste "novo sujeito feminista político, plural, abrangente das mulheres de diversos sectores sociais" (p. 662), que tem que ser encarado numa perspetiva interseccional. Este é o desafio final da autora, numa obra que, além de fomentar a reflexão, inquieta, leva a questionamentos e, acima de tudo, abre a possibilidade de diálogo. Um manual essencial para qualquer pessoa que se interesse por estas questões, para estudantes na área, para as novas gerações que não passaram por todas estas transformações sociais e que devem ter presente que todo o conhecimento é localizado.

\section{Carla Cerqueira}

\section{Figueiredo, Elisabete (org.) et al. (2011), O rural plural - Olhar o presente, imaginar o futuro. Castro Verde: 100Luz, 494 pp.}

A colectânea "O rural plural" em meia dúzia de traços

O rural plural-Olhar o presente, imaginar o futuro é o livro que abre a colecção "Territórios da Mudança”, sendo apoiado pela SPER (Sociedade Portuguesa de Estudos Rurais) e pela Universidade de Aveiro. Editado pela 100Luz, faz luz. É colectânea com peso, quase 500 páginas de papel reciclado, que une 53 autores a 33 textos. Ou seja, é vincado o seu pendor colectivo, sendo um extracto aromático da centena de orações ofertadas ao IV Congresso de Estudos Rurais, 2010. Desta reunião o livro herda a estrutura, que se demarca logo num pórtico triplo, erguido com os textos de E. Figueiredo, F. O. Baptista e A. Covas, todos eles perscrutando a "bola de cristal" rural. O intróito primeiro, habilmente ornado com poemas interpeladores, certeiros, faz muito bem o que é esperado.
Seguem-se mais quatro divisões, onde se observam os dias de hoje e, nalguns casos, se imagina o amanhã, isto quanto à agricultura; turismo; políticas públicas; actores e dinâmicas no meio rural. O título e subtítulo da obra ajustam-se ao seu teor poliédrico. O plano e o lugar das partes poderiam ser outras, mas a arquitectura do todo tem arte, sendo de realçar que cada componente possui unidade e coerência interna.

Esta obra é fruto do labor de 32 mulheres e 21 homens. Note-se que as obreiras dominaram não só o processo de produção mas também a gestão do produto. Só na coordenação deste há seis mulheres e um homem, meio escondido entre elas. De mangas arregaçadas, a dona da obra mais outra parceira, às quais se uniram várias coadjutoras e três ajudantes, inscreveram-se em mais de $20 \%$ dos textos. A hegemonia 
feminina revela-se ainda no seguinte. Por um lado, as mulheres, quer unidas entre si, quer colaborando com varões, imperam nas co-autorias. Em 18 destas, as achegas femininas predominam em $12 \mathrm{e}$ nos 15 textos de autoria simples sete têm só mão de mulher. Por outro lado, a união intragénero masculino é rara: há só uma co-autoria entre homens (um texto luso-brasileiro) e num total de oito trios só em dois os homens sobressaem.

Para lá do sexo, idade, e treino disciplinar inicial, há variações notórias de sensibilidade (v.g. ecológica, iconográfica, social e política) entre os feitores desta obra. Igualmente marcada é a sua "biodiversidade". Eles cruzam fases bem distintas do seu currículo: vemos, assim, tanto o catedrático ora reformado e que inicia uma nova colecção editorial como o jovem que foi espicaçado a extrair da sua própria tese a primeira comunicação (a oral e a escrita). E, entre estes pólos, os restantes mestres, doutorandos e doutorados. A par desta variação de identidade pessoal, estende-se uma outra escala, a relativa à natureza do artigo ou projecto subjacente (onde, em regra, sobressaem métodos qualitativos): num caso, trata-se de um texto teórico; noutro, tão-só um repositório empirista; num outro exemplo, a pesquisa é exploratória ou o caso respectivo apenas emerge; noutros casos os textos espelham pensamento amadurecido, síntese de trabalhos de uma mesma série, obra acabada. Importa, desde já, aclarar que à volta de um quarto dos textos de "O rural plural" e um quarto dos autores se acham ligados a teses de mestrado e/ou a estudos de cariz exploratório. $\mathrm{O}$ estilo e o tom da palavra reforçam a heterogeneidade do livro: está aqui tanto o autor que redige admiravelmente como o que tão-só se cita a si próprio, ou é verboso, ou telegráfico, estes últimos clamando por mais práxis oficinal.
Muitos dos subscritores da obra (45/53) trabalham em instituições repartidas por todo o país, sobretudo em quatro politécnicos e sete universidades públicas. Note-se, ainda, que há cinco autores oriundos de três universidades brasileiras, duas investigadoras vindas de dois institutos nacionais do México e um estudioso português na Universidade da Carolina do Norte. A rematar a faceta "global" do livro, diga-se ainda que entre as autoras conta-se uma canadiana que investiga em Coimbra. O contingente das universidades lusas sobe a 33 autores e cerca de metade são, digamos, aveirenses. É caso para dizer que a Universidade de Aveiro não deixa crédito em mãos alheias, mas, mesmo assim, os lisboetas montam a uma dezena.

Em "O rural plural" o tempo é o de hoje e o de amanhã, mas acham-se muitas geografias e todas as escalas. Dá-se a volta à terra, embora não se faça escala nem em África, nem na Ásia. O plano intercontinental está presente, quer no texto que une comunidades rurais dos Países Baixos, Austrália, Canadá e EUA através da arte e da cultura (vide N. Duxbury), quer naquele que liga, em voo turístico de longo curso, o segundo mundo ao velho continente (vide A. Rodrigues et al.): acaso não sabemos que há americanos com nostalgia da Europa? O plano nacional subjaz ao artigo sobre a política de desenvolvimento rural no México (vide M. Flores et al.); num outro relativo ao Brasil, onde se abrem os quadros sucessivos do programa de agro-industrialização da agricultura familiar animado sob os governos Lula (2003-2010), mas avulta ainda numa dezena de textos relativos a Portugal continental. Aqui, o plano regional recebe as honras do livro. Percorrem-se todas as grandes regiões do país, embora o passo seja rápido no Alentejo (vide D. Sampaio et al.). A demora dá-se nas Beiras, em particular na Serra da Estrela, mas não só de território montanhoso se faz o meio rural 
e a obra sob apreço. Também a cidade, a grande e a pequena, e as suas sombras incidem sobre terras e gentes do campo, como se sabe e bem revelam dois textos. Um, focado na freguesia de Santa Susana, concelho de Alcácer do Sal, local de transição entre a Área Metropolitana de Lisboa e o Alentejo (vide D. Sampaio et al.); aqui, a $10 \mathrm{~km}$ do núcleo histórico, assenta um condomínio privado de 40 moradias, vedado e vigiado durante todo o dia, a dita Vila Nova de Santa Susana. Outro, o texto focado no Assentamento Dom Tomás Balduíno, na zona periurbana da Grande São Paulo (vide T. Brosler et al.). Aqui achamos 50 famílias, ex-sem-terra e ora em área declivosa e pouco produtiva da Fazenda São Roque, de quem se pode dizer: "seus antepassados saíram do rural e eles saíram do urbano”. A propósito, diga-se ainda que também as gentes da urbe sofrem, desde tenra idade, da apologia da cidade e do inculcar da ideia de que "a boa ruralidade é aquela em que se consegue ascender à condição urbana" (vide S. Claudino).

Esboçada a figura de "O rural plural", é hora de indagar dos seus préstimos. Antes de mais, este livro é útil pela informação rica e diversa que faculta. Por exemplo, um vasto espólio de fontes e referências bibliográficas, onde se inclui uma obra, no prelo, de um historiador consagrado (C. Torres, "Alentejo agrícola"); um manancial de dados quantitativos sobre o PRIME (Programa de Incentivos à Modernização da Economia), em especial o financiamento do turismo em 2000-06 (S. Silva et al.) e uma descrição minuciosa sobre a acção dos GAL (Grupos de Acção Local) quanto ao turismo em áreas rurais (G. Dinis et al.); ou um rol copioso de casos que ilustram a noção de biodiversidade (F. Barros et al.): mesmo informados que se trata da Amazónia, não é de pasmar que os ribeirinhos do Riozinho do Anfrísio cultivem mais de
40 espécies vegetais e que só para os casos da mandioca e da banana aproveitem mais de 10 variedades de cada planta?

A este total some-se outra parcela. Vários autores identificam vazios de saber, a explorar como filões promissores. É o caso de A. Rodrigues et al. que, para lá de aludir à sociologia da nostalgia, nos faz saber que aquela noção tem vindo a ser estudada na esfera do comportamento do consumidor, mas que há poucos estudos que a abordem no quadro turístico (p. 232). C. Vieira et al., igualmente, afirma que é relativamente escassa a pesquisa que se centra na articulação entre o turismo e o agro (p. 108). De modo similar A. Dinis afirma a escassez lusa em estudos sobre o empreendedorismo e o empresário rural (p. 397). Também N. Duxbury declara que os papéis e desafios adoptados por artistas e indústrias culturais e criativas no quadro do desenvolvimento comunitário rural são por vezes pouco escrutinados pelos especialistas em desenvolvimento rural (p. 164). O capital deste livro amplia-se ainda mais por via dos contributos teóricos-metodológicos que propõe. Entre outras, uma das achegas leva-nos a tomar a sério o "empreendedorismo estilo de vida" (C. Cunha et al.); outra o papel crucial do Estado face ao empreendedorismo em zonas rurais desfavorecidas (M. B. Moreira). Aqui se defende que em vez de se investir na noção de tipo individual se deve apostar em "uma abordagem alternativa baseada nos conceitos de função empresarial necessária, de falhas de mercado e de falhas de estado, onde a função empresarial necessária seja equiparada a bem público" (p. 389). Um terceiro texto explora a integração de variáveis de cariz social na avaliação do risco de incêndio florestal (M. Rodrigues et al.) e um outro expõe-nos a metodologia WOCAT (World Overview of Conservation Approaches and Technologies) (S. Valente et al.). 
Nalguns artigos várias autoras iluminam as caves do ignorado, assim elevando o mérito geral do livro. Num caso, por exemplo, pesam-se os sentidos e o valor da produção para o autoconsumo na agricultura familiar do Rio Grande do Sul (C. Grisa); num outro faz-se luz como através da pêra Rocha se tem vindo a construir a identidade territorial-simbólica do Oeste luso (M. Truninger et al.); e num terceiro exemplo, bem travejado teórica e empiricamente, ficamos a matutar quanto ignoramos o chão miudinho do Norte, em particular o denso legado agrícola incrustado nas micro- e pequenas empresas industriais (I. Rodrigo). Falta espaço para aludir a outros pontos e textos, mas seria erro não destacar o artigo claro, conciso e crítico de F. O. Baptista. Aqui se anuncia a passagem da propriedade agrícola à propriedade ambiental e se denuncia a posse de "terras que sobram da produção agrícola mas que, por vezes, ainda são ocultadas na informação estatística. Assim, cerca de metade da designada superfície agrícola utilizada (SAU) é gerida para maximizar subsídios e não com qualquer critério produtivo ou de criação de emprego. Tem-se mesmo assistido ao aumento desta superfície através da sua componente pastagens pobres, utilizando esta designação de modo eufemístico para que terrenos incultos, e que assim continuam, possam ser considerados para o proprietário receber mais subsídios". No dito texto se menciona ainda que muitas áreas de floresta difundem igualmente uma "imagem de desmazelo e subaproveitamento". Consequentemente, e retomando uma questão velha, o autor defende que "não basta [...] 'imaginar o mundo transformado', importa também imaginar o seu 'processo de transformação' ou, pelo menos, os obstáculos que possa encontrar: no caso, o que impede afinal que a terra, limitada e não reprodutível, seja um espaço de acolhimento para as populações, tanto para enraizarem a vida e o trabalho, como para a percorrerem e sentirem" (pp. 54-57).

Aos serviços que esta colectânea nos presta, temos de juntar um outro, aliás inscrito em vários textos: o combate justo e saudável quer ao optimismo vazio e irreflectido acerca do desenvolvimento rural, quer ao pessimismo infundado. A. Cristóvão et al. e P. Batista et al., entre outros, mostram que o trilho pode ser longo, árduo e com retrocessos. Mas, como indica o saber disponível, aquela terra prometida pode ser alcançada. Isto, sob certos cuidados, entre eles os seguintes: renovar lideranças, ser ouvido e ser instado a falar, dar continuidade à acção nas comunidades rurais (J. A. Correia et al.); desenvolver a participação para a participação no desenvolvimento (J. Colaço), práxis difícil, que não raro pode ser mera encenação simbólica; instaurar novas formas de governação, começando por reconhecer que urge colocar terras e gentes rurais num lugar central das políticas públicas a fim de cumprir as metas de desenvolvimento e coesão social (M. A. Henriques); promover a "intervenção global e integrada, em várias frentes", para se superar, por exemplo, a dissociação entre a gastronomia regional e a restauração local (C. Vieira et al.), ou para materializar e consolidar as ZIF (Zonas de Intervenção Florestal ) (S. Valente et al.), ou ainda para se produzirem orientações específicas nas autarquias onde a "montanha" prevalece (G. Fernandes et al.); enfim, é crucial pensar as aldeias primeiro "como espaços de vida em comunidade, assente no acesso a trabalho digno, rendimento justo e serviços de qualidade, e só depois como locais de recreio e lazer" (A. Cristóvão); de outro modo, chegar-se-á a situações como as observadas no Algarve Rural: "passeios de jipe que visualmente passam a imagem da visita à selva; almoços em pacote onde o "frango assado" é assumido como 
especialidade regional; "o golfe como nova forma de agricultura" (V. Sousa).

Aqui chegados seria falha não aludir mais especificamente ao plano formal da colectânea, que depende tanto ou mais dos autores quanto dos seus coordenadores e editor. É certo que só obra de Deus é perfeita, mas para lá das gralhas inesperadas e sempre irritantes, é mister indagar sobre facilitismos que atentam contra o que se espera na ciência, por exemplo, as citações em segunda mão de autores vivos e cujos textos estão $100 \%$ acessíveis; o copy and paste repetidos; e, quadros e figuras que não permitem a leitura autónoma. Em suma, duas ideias para novos Territórios da Mudança: é curial subir a fasquia da exigência formal dos textos a publicar e vale a pena apostar na revisão e na normalização editorial. É claro que este tipo de labor final não foge à razão custos/benefícios, mas estes cresceriam muito se tais exercícios da oficina da escrita, para lá de enfadonhos, fossem pautados por mais rigor.

Pelos traços, limites e limitações, bem como méritos de "O rural plural", não se estranhará que incitemos um público vasto e variado à leitura da obra: no geral, prazer e proveito serão benefícios seguros. Muito menos causará surpresa que reconheçamos que a obra coroa muito oportunamente a árdua mobilização de predisposições e vontades ocorrida antes e depois do IV CER. Como não lembrar aqui e agora a grande onda brasileira que chegou à Ria? Que mar imenso de ideias, vontades, recursos, energia e acções foi preciso navegar para aqui chegar? É, pois, justo dizer a Elisabete Figueiredo et al.: bem-hajam pela coragem, resistência e labor postos em toda a empresa. Dos fracos não reza a história.

José Portela 